\title{
AS CONTRIBUIÇÕES DA COMPETÊNCIA CRÍTICA EM INFORMAÇÃO NAS PRÁTICAS INFORMACIONAIS DE ESTUDANTES QUILOMBOLAS NO ENSINO SUPERIOR: RELATO DE PESQUISA
}

\author{
THE CONTRIBUTIONS OF THE CRITICAL \\ INFORMATION LITERACY IN THE INFORMATIONAL \\ PRACTICE OF QUILOMBOLA STUDENTS IN THE \\ HIGHER EDUCATION: RESEARCH REPORT
}

Maria Ivone Maia Costaa

Renata Lira Furtado Correiob

\begin{abstract}
RESUMO
Objetivos: Analisar dentro de um contexto histórico, social e cultural, as práticas informacionais dos estudantes quilombolas na Universidade Federal do Pará, com o intuito de contribuir para a elaboração de ações afirmativas, com a perspectiva de minimizar a problemática de acesso à informação enfrentado por esses sujeitos. Metodologia: Pesquisa qualitativa dividida em três etapas: a primeira apresenta uma pesquisa bibliográfica; na segunda etapa apresenta-se o desenvolvimento da pesquisa, na qual estão incluídas a pesquisa documental que possibilitou traçar um panorama acerca da presença dos estudantes quilombolas matriculados na instituição; uma pesquisa etnográfica, com a aplicação de um questionário no google forms e de uma entrevista semiestruturada. Os dados foram analisados sob os fundamentos da Análise Crítica do Discurso e na terceira etapa desenvolveu-se a triangulação dos dados obtidos nas etapas anteriores. Resultados: Indicam que as práticas informacionais desenvolvidas pelos estudantes quilombolas no campo acadêmico e no campo das comunidades tem uma interação social, demonstrando uma criticidade nas ações informacionais. Conclusões: As ideias desenvolvidas nesta investigação contribuem principalmente para a concretização de ações práticas e geração de conhecimentos fundamentais nas questões das desigualdades sociais e culturais dentro do contexto pesquisado.
\end{abstract}

Descritores: Práticas Informacionais. Estudantes quilombolas. Competência Crítica em

\footnotetext{
a Mestra em Ciência da Informação pela Universidade Federal do Pará (UFPA). Bibliotecária /Documentalista da Universidade Federal do Pará (UFPA). E-mail: ivomcost@gmail.com.

b Doutora em Ciência da Informação pela Universidade Estadual Paulista (UNESP). Docente no Programa de Pós-Graduação em Ciência da Informação e no curso de graduação em Arquivologia na Universidade Federal do Pará (UFPA). E-mail: renatalira@ufpa.br.
} 
Informação.

\section{INTRODUÇÃO}

O avanço tecnológico possibilita cada vez mais o acesso aos meios de comunicação e de informação, no entanto, é observada uma discordância entre o desenvolvimento científico e o social no que se refere à informação, evidenciando que a apropriação da informação vai além do processo de busca e uso da informação. Assim, as práticas informacionais tornaram-se mais dinâmicas, principalmente pelo uso de fontes de informação não formais, o que requer do indivíduo um pensamento crítico como forma de enfrentamento para lidar com o grande volume de informações. Consequentemente, esse cenário acentua a exclusão das minorias no acesso à informação. Nesse sentido, a informação colabora para a construção do conhecimento e desperta um posicionamento crítico diante da quantidade de informações.

Os estudos das práticas informacionais visam ao incentivo da interação do sujeito informacional em diferentes contextos e de maneira coletiva e individual (ARAÚJO, 2013). A proposta dessa pesquisa foi construída objetivando associar as práticas informacionais de estudantes quilombolas no ensino superior com a Competência Crítica em informação (CCI), com destaque na vida cotidiana, o aprendizado ao longo da vida e o pensamento crítico como forma de incentivar discussões que contribuam para elaboração de ações alternativas no enfrentamento das desigualdades sociais vivenciadas por esses sujeitos no contexto pesquisado.

Identificar a vivência desses estudantes quilombolas dentro da universidade e na vida cotidiana das comunidades torna-se relevante para compreender a complexidade das temáticas étnico-raciais, e assim estimular discussões que fortaleçam a abordagem social das práticas informacionais na Ciência da Informação.

Diante do exposto, o objetivo da pesquisa foi realizar uma análise dentro de um contexto histórico, social e cultural das práticas informacionais dos estudantes quilombolas da Universidade Federal do Pará (UFPA), com o intuito de contribuir para a elaboração de ações práticas que desenvolvam o 
pensamento crítico nessas pessoas. Esses aspectos cooperam para ressaltar o compromisso da Instituição com a produção de conhecimento e com a responsabilidade social. $\mathrm{O}$ acesso ao ensino superior é apenas um aspecto da democratização da educação, pois a sua concretização necessita da construção de ações que assegurem a permanência e a legitimidade desse grupo historicamente excluído nas universidades. Sendo assim, acredita-se que as práticas informacionais desenvolvidas por estudantes quilombolas no ensino superior proporcionam uma interação participativa com a história da Instituição.

A análise das práticas informacionais discorre questões acerca dos aspectos fundamentais emanados da vida cotidiana do sujeito, como memória, cultura e história de uma comunidade tradicionalmente marcada por conflitos e por exclusão. Logo, os estudos de usuários no campo da Ciência da Informação, com uma tendência voltada para uma abordagem social possibilita criar perspectivas para análise do fenômeno informacional, com reflexões mais complexas sobre os sujeitos.

\section{PROCEDIMENTOS METODOLÓGICOS}

Para o desenvolvimento da pesquisa optou-se por uma estrutura metodológica qualitativa, dividida em três etapas. A primeira etapa refere-se à sistematização teórica, produto da pesquisa bibliográfica, desenvolvida com reflexões sobre as abordagens teóricas relativa às práticas informacionais, à Competência Crítica em Informação e a história dos quilombolas no Brasil, especialmente em torno da sua luta pela educação, do acesso ao ensino superior e a compreensão da trajetória histórica, cultural e social dos sujeitos da pesquisa.

$\mathrm{Na}$ segunda etapa apresenta-se o desenvolvimento da pesquisa, na qual estão incluídas a pesquisa documental que possibilitou identificar os estudantes quilombolas matriculados em cursos de graduação na Universidade Federal do Pará, e a pesquisa etnográfica, que possibilitou não apenas a coleta de dados, mas interpretar e compreender os fenômenos sociais, comportamentos e interações do grupo em estudo para evidenciar uma realidade concreta vivenciada pelos sujeitos, que chegam ao ensino superior com uma defasagem educacional, problemática de uma educação que Ihe foi sempre negada. 
Ao considerar as condições sanitárias no contexto da pandemia de Covid19 e consequentemente, a dificuldade de se localizar esses estudantes optouse pela técnica de amostragem não probabilística para definir o corpus a ser investigado. A técnica de Snowball Sampling traduzida como Amostragem Bola de neve, que é utilizada em pesquisas sociais mostrou ser viável quando inexiste a possibilidade de determinar a seleção dos participantes da pesquisa ou quando se tem dificuldade em ter acesso a determinadas comunidades.

O questionário no google forms foi a ferramenta utilizada para alcançar o maior número de sujeitos e assim realizar a entrevista semiestruturada on line, composta de um roteiro de 12 questões. Para a análise dos dados, a pesquisa seguiu a proposta da Análise Crítica do Discurso (ACD) de Norman Fairclough (2001) em que o discurso se baseia na análise tridimensional, isto é o discurso pode ser entendido como Texto, como Prática discursiva e como Prática social. A leitura das entrevistas definiu as categorias e as subcategorias que direcionaram as análises dos dados, sendo as categorias Hegemonia e Ideologia fundamentada na prática social da ACD, e as subcategorias baseadas nos relatos das entrevistas. A terceira etapa definida como triangulação consistiu em relacionar os resultados da análise com as possíveis contribuições da Competência Crítica em Informação no desenvolvimento das Práticas Informacionais.

\section{PRÁTICAS INFORMACIONAIS E COMPETÊNCIA CRÍTICA EM INFORMAÇÃO: PERCEPÇÕES TEÓRICAS}

Na perspectiva histórica da Ciência da Informação são apontados vários estudos e diferentes pontos de vista que influenciaram o desenvolvimento da área. Entretanto, a fundamentação epistemológica do campo está relacionada a três paradigmas: o físico, o cognitivo e o social, que contribuíram para o desenvolvimento e evolução das subáreas, principalmente os estudos de usuários.

O paradigma social ou pragmático nasce das críticas ao modelo cognitivo fundamentado sob uma perspectiva fenomenológica, na qual se busca inserir os sujeitos no mundo, assim como se preocupa com os processos informacionais 
voltados para o social. Na Ciência da Informação o paradigma social evidencia o caráter construtivo da informação e do conhecimento. Os usuários são vistos a partir de contextos sociais e culturais e podem ser qualificados como sujeitos informacionais. Esse entendimento provavelmente colaborou para um novo olhar nos estudos de usuários com uma proposta fundamentada no social e no coletivo, em uma interação que gera um fortalecimento das pessoas tornandoas mais participantes e atuantes em múltiplos contextos, como o social, o cultural, o econômico, o político, o organizacional e o afetivo reafirmando uma visão da informação que vai além do cognitivo. (ARAÚJO, 2012; GONZÁLEZ TERUEL, 2005).

Nesse contexto da abordagem social surgem os estudos das Práticas Informacionais com Reijo Savolainen em 1995 baseando-se no conceito de habitus para enfatizar a importância dessa nova expressão no processo de busca, de uso e de compartilhamento da informação, dando um contexto mais amplo para as interações estabelecidas entre os sujeitos e a informação. Desse modo, a construção das práticas informacionais pelos sujeitos sociais é resultado de suas atividades desenvolvidas no cotidiano, assim "podem ser conceituadas como ações de recepção, geração e transferência de informação que se desenvolvem em circuitos comunicacionais que ocorrem nas formações sociais". Por outro lado, a informação é um operador de relação, ou ainda um indicador de mediação que possibilita e é possibilitado pelas relações sociais (ARAÚJO, 1999, p. 155).

Além disso, as práticas informacionais não se prendem a uma sequência padronizada de necessidade, de busca e de uso da informação, mas a um conjunto de elementos que segundo Ferreira et al. (2019) relaciona a compreensão da informação pelo sujeito a partir da prática e da ação, gerando um processo que envolve a vivência individual e coletiva, e, à medida que suas ações forem desenvolvidas, elas podem provocar uma mudança no cenário no qual estão inseridas. São perspectivas que podem contribuir e impulsionar a apropriação e disseminação da informação por sujeitos discriminados socialmente, assegurando um aprendizado que desperte necessidades informacionais com pensamento crítico. 
Sendo assim, as discussões sobre as Práticas informacionais e a Competência Crítica em Informação (CCl) levantam questões sobre a autonomia e a interação cotidiana informacional em diversos contextos sociais, uma vez que a $\mathrm{CCl}$ acentua a dimensão, a abrangência e as questões referentes à importância da prática do pensamento crítico na Competência em Informação (Colnfo), elemento que corrobora para a adequação dessa temática ao acelerado avanço das tecnologias de informação e de comunicação e incentivam o indivíduo a desenvolver uma perspectiva crítica em complemento às atividades de busca, de uso da informação e da construção do conhecimento.

Segundo Elmborg (2012) a inserção da palavra crítica à Colnfo se deu por meio de dois fatores: o primeiro está relacionado ao desenvolvimento de novas práticas e o segundo relaciona-se com o estabelecimento de uma ação crítica frente as atuais práticas de padrões de competência em informação, que são relevantes, mas que impedem a formação de outras possibilidades, como ampliação dos sujeitos e dos contextos (ELMBORG, 2012).

Vale destacar que a CCl está fundamentada na Teoria Crítica dos filósofos da Escola de Frankfurt e na Pedagogia Crítica de Paulo Freire. Os estudos sobre a Teoria crítica a consideram como um projeto para contrapor a chamada teoria tradicional, não se limitava em apenas observar o mundo e seguir padrões, mas imaginar como o mundo poderia ser objetivando mudanças a partir de uma prática transformadora que se constituída por meio de uma ação ética acrescida de liberdade e de autonomia promoveria a emancipação de qualquer forma de dominação (FLECK, 2017). Na Pedagogia crítica de Paulo Freire, os fundamentos estão pautados em uma teoria educacional crítica e libertadora que visa conscientizar e capacitar o sujeito na compreensão crítica relacionada à produção de conhecimento direcionada a uma emancipação social. A contribuição da Pedagogia crítica tem como característica o desenvolvimento de uma consciência crítica fazendo com que os estudantes se apropriem do controle de suas vidas e de seu próprio aprendizado transformando-se em indivíduos ativos (TEWELL, 2015).

Entende-se que esses fundamentos teóricos críticos vão dar complementaridade à $\mathrm{CCl}$ e proporcionar uma emancipação social com objetivo 
de despertar um valor moral, igualitário e autônomo aos cidadãos, ou seja, desenvolver uma percepção sobre como conduzir os debates sobre os conflitos, desigualdades sociais e exclusão de minorias ao acesso à informação. Face a esse panorama, entende-se que a CCl é um campo fértil para desenvolver ações práticas frente à realidade informacional contemporânea.

Diante disso, a $\mathrm{CCl}$ contribui com o conceito tecnicista e instrumental da Competência em Informação agregando elementos como o pensamento crítico e o uso ético da informação e considera, além dos fatores sociais, culturais e econômicos, o cotidiano e não apenas o uso e a busca eficiente da informação. Essa aplicação do pensamento crítico é apresentada por Schneider (2019), que estruturou a noção de $\mathrm{CCl}$ em sete níveis, conforme apresentado no Quadro 1.

\section{Quadro 1 - Níveis de Competência Crítica em Informação}

\begin{tabular}{|c|l|}
\hline CCI/7 & \multicolumn{1}{|c|}{ Diretrizes para mediadores e usuários da informação } \\
\hline $\begin{array}{c}10 \text {. Nível da } \\
\text { concentração }\end{array}$ & $\begin{array}{l}\text { Suspensão da cotidianidade, foco de toda a atenção em um determinado } \\
\text { problema ou conjunto de problemas, abstração da espontaneidade, do } \\
\text { imediatismo, dos juízos provisórios, das generalizações, da mimese, dos } \\
\text { preconceitos }\end{array}$ \\
\hline $\begin{array}{c}2^{\circ} \text {. Nível } \\
\text { instrumental }\end{array}$ & $\begin{array}{l}\text { Conhecimento dos recursos informacionais existentes e domínio técnico das } \\
\text { tecnologias de informação }\end{array}$ \\
\hline $\begin{array}{c}3^{\circ} \text {. Nível do } \\
\text { gosto }\end{array}$ & $\begin{array}{l}\text { Problematização da noção de necessidade informacional, aliada ao estímulo à } \\
\text { curiosidade intelectual e à formação do gosto pelo pensamento questionador e } \\
\text { rigoroso }\end{array}$ \\
\hline $\begin{array}{c}4^{\circ} \text {. Nível da } \\
\text { relevância }\end{array}$ & $\begin{array}{l}\text { Questionamento sistemático da relevância da informação e da própria noção de } \\
\text { relevância, bem como dos mecanismos e dos critérios sociotécnicos de atribuição } \\
\text { de relevância aos enunciados, aos dados e aos metadados }\end{array}$ \\
\hline $\begin{array}{c}5^{\circ} \text {. Nível da } \\
\text { credibilidade }\end{array}$ & $\begin{array}{l}\text { Questionamento sistemático da credibilidade das fontes de informação e dos } \\
\text { produtores de dados e metadados, bem como dos mecanismos e dos critérios } \\
\text { sociotécnicos de atribuição de credibilidade às fontes, e aos produtores de dados } \\
\text { e metadados }\end{array}$ \\
\hline $\begin{array}{c}6^{\circ} \text {. Nível da } \\
\text { ética }\end{array}$ & $\begin{array}{l}\text { Reflexão séria e responsável sobre o bem ou o mal, resultante dos usos da } \\
\text { informação, com ênfase nos problemas articulados da mentira, da opressão e do } \\
\text { sofrimento, numa perspectiva intercultural, sem perder de vista as contradições } \\
\text { entre o singular, o particular e o universal }\end{array}$ \\
\hline $\begin{array}{c}7^{\circ} \text {. Nível da } \\
\text { crítica }\end{array}$ & $\begin{array}{l}\text { Articulação de todos os níveis anteriores em uma perspectiva emancipatória } \\
\text { realista, bem como da própria noção de realismo, a partir do conhecimento das } \\
\text { teorias sociais críticas e das teorias críticas da informação. }\end{array}$ \\
\hline
\end{tabular}

Fonte: Schneider (2019, p. 109)

Os níveis discutidos por Schneider (2019) são uma forma de entender a inflexão crítica presente na $\mathrm{CCl}$, a partir da Competência em Informação. Em cada um desses níveis citados, os mediadores e os usuários de informação podem perceber o sentido crítico possibilitando uma nova reflexão sobre as necessidades informacionais. Nessa abordagem o autor, destaca as ideias de 
Bourdieu sobre a dominação simbólica e o habitus, no sentido de expor o quanto a alienação pode subjugar os indivíduos, e como pode ocorrer o enfrentamento diante dos problemas éticos informacionais, dos regimes de informação e da disseminação de informação sem filtros no meio de grupos sociais menos favorecidos.

Destarte, ao realizar a pesquisa sobre as temáticas Práticas Informacionais e Competência Crítica em Informação foram observadas que ambas compartilham ideias relacionadas às questões sociais, políticas e culturais. Além disso, ainda discutem a informação, não somente como um processo de necessidade e de uso, porém sob uma perspectiva de impulsionar o sujeito para um aprendizado contínuo, com a pretensão de estimular reflexão crítica e ética sobre as informações e a autonomia para interferir nas mudanças sociais. Acredita-se que em torno desses conceitos teóricos surjam novas contribuições para que a $\mathrm{CCl}$ seja desenvolvida e assimilada pelos indivíduos validando um melhor uso das práticas informacionais, e elaborar novas ações.

\section{QUILOMBOLAS NO ENSINO SUPERIOR}

Com o propósito de compreender a trajetória histórica e social dos quilombolas até o seu ingresso ao ensino superior foram abordados temas sobre a escravidão, a invisibilidade, as lutas, a exclusão social, e as heranças de desigualdades sociais que se perpetuam até hoje. Esses fatores fazem parte das lutas dos movimentos sociais e promovem ações para reivindicar os direitos das comunidades remanescentes de quilombos, principalmente pela educação.

Nesse cenário, cabe destacar marcos importantes que ocorreram no Brasil: criação do Ministério da Educação e Saúde Pública (1930) - que passou a ser Ministério da Educação e Cultura (1953) e o Conselho Nacional de Educação (1930); publicação de um Manifesto dos Pioneiros da Educação Nova (1931), propondo um novo perfil de ensino; a redemocratização do país iniciada, nos anos 80 , também possibilitou a emersão de um novo perfil intelectual na abordagem de temas sobre as relações raciais, sobretudo no campo educacional. Essa questão ganhou atenção nas ações e lutas da população negra e se tornou uma das maiores reivindicações do movimento negro, no 
século XX. Este movimento ressalta que a educação unicamente não extinguirá todos os problemas, mas contribui em vários processos, como: "produção de conhecimento sobre si e sobre "os outros", na formação de quadros intelectuais e políticos e é um critério usado pelo mercado de trabalho para selecionar e excluir pessoas" (CARRIL, 2017; GOMES, 2011, p. 112).

Outro marco foi a Lei 10.639, de 9 de janeiro de 2003 que estabelece as diretrizes e bases da educação nacional, para incluir no currículo oficial da Rede de Ensino a obrigatoriedade da temática "História e Cultura Afro-Brasileira", o Parecer CNE/CP ${ }^{1}$ 03/2004 e a Resolução CNE/CP 01/2004, estabeleceu como obrigatório no ensino fundamental e médio, oficial e particular, o ensino sobre História e Cultura Afro-Brasileira. Considera-se uma conquista em relação à educação em geral e para comunidades quilombolas. Uma ação que tem como objetivo de resgatar o sentimento de pertencimento étnico-racial e o reconhecimento de sua identidade, memória e cultura, reivindicadas pelo Movimento Negro e demais movimentos. (BRASIL, 2004).

Essa conquista que tem 17 anos, ainda não teve uma implantação de forma efetiva. São evidentes as situações de exclusão de alunos, seja pela falta de escolas, seja pela falta de projeto pedagógico elaborado em concordância com a realidade social, histórica, cultural, identitária e territorial. É observada ausência de diálogo entre o que a lei determina, a realidade e a especificidade das comunidades quilombolas no Brasil e os órgãos públicos responsáveis. Quando não há comprometimento com as políticas públicas no ensino básico de qualidade, a possibilidade de acesso ao ensino superior por famílias quilombolas é quase improvável.

Em relação ao ensino superior, a Lei o‥12.711, de 29 de agosto de 2012, provoca uma adesão das universidades públicas à nova política que dispunha sobre o regime de vagas para estudantes egressos do ensino público: pretos, pardos e indígenas. Ainda que não exista nessa legislação uma especificação sobre o acesso de estudantes quilombolas, algumas universidades, no uso de sua autonomia, disponibilizam vagas para essas comunidades. A ação de movimentos sociais evidenciou a necessidade de discutir o direito de acesso ao

\footnotetext{
${ }^{1}$ Conselho Nacional de Educação/Conselho Pleno
} 
ensino superior para todos, com a inclusão de forma justa de estudantes de todas as classes sociais e raças (FERES JÚNIOR; DAFLON, 2014; CAMPOS, 2016).

Salienta-se que as políticas de ações afirmativas são medidas fundamentais para combater a discriminação e exclusão social nas instituições públicas de educação superior e têm como funções:

\begin{abstract}
Reparar o passado discriminatório, em que diferentes seguimentos estão inscritos, como medida compensatória; busca alcançar o campo da igualdade, em relação ao acesso a Universidade, tendo como objetivo corrigir desequilíbrio no campo educacional, além da construção de mecanismos que combatam a desigualdade social (LIMA et al., 2015, p. 5).
\end{abstract}

Em meio a esse panorama a implantação da reserva de vagas para alunos quilombolas na UFPA foi realizada a partir de ações afirmativas. A Resolução no. 4.309, de 27 de agosto de 2012, determinou a reserva de duas vagas para alunos quilombolas nos cursos de graduação da instituição. No entanto, para chegar a essa resolução, foram necessários vários debates, iniciados por volta de 2004, tendo à frente o Movimento Negro Paraense e a Pró-Reitoria de Ensino e Graduação (PROEG) da UFPA. Essas representações elaboraram uma proposta de ações afirmativas que deliberou garantias mais democráticas de acesso e de permanência dos grupos étnicos e discriminados aos cursos de graduação da UFPA.

Apesar de ter sido aprovado em 2012, o ingresso dos discentes quilombolas aconteceu de fato somente em setembro de 2013, quando ocorreu o primeiro Processo Seletivo Especial para quilombolas na UFPA, com início do ano letivo em 2014. Essa demora no cumprimento da resolução indica barreiras na realização dessas ações na UFPA. Contudo, é importante ressaltar que esse processo configura um avanço na política de acesso à Universidade (UFPA, 2012; LIMA et al., 2015; CAMPOS, 2016).

Entende-se que a universalização da educação é um processo lento e ao longo da história não houve preocupação em reparar a discriminação e a exclusão dos povos quilombolas. O que se vê no campo educacional é a constante produção e reprodução de um quadro de desigualdades raciais. Não 
se admite o papel ideológico da escola em tratar os alunos, "como se todos fossem iguais, reproduzindo um ideal abstrato dos sujeitos, ao mesmo tempo, transmitindo uma neutralidade em seus conteúdos curriculares" (CARRIL, 2017, p. 551). Essas são conquistas importantes, mas ainda são necessários avanços, principalmente em relação a permanência desses estudantes na universidade, e dando continuidade ao processo de reparação de séculos de exclusão e de discriminação. Esses sujeitos agora têm acesso ao ensino superior, mas a universidade ainda invalida seus saberes e suas vivências.

\section{APRESENTAÇÃO E ANÁLISE DOS RESULTADOS}

Os primeiros resultados deste estudo foram decorrentes da pesquisa documental que, por meio de um documento emitido pelo Centro de Registros e Indicadores Acadêmicos (CIAC), da UFPA, foi possível identificar o quantitativo de alunos quilombolas matriculados em cursos de graduação, a relação de cursos, bem como a localização geográfica. São, portanto, $2.148^{2}$ alunos quilombolas em toda a instituição, distribuídos em distintos campus, polos e núcleos localizados em municípios do interior, e no Campus Belém, situado na capital do Estado. Esses discentes estão matriculados em 69 cursos de graduação distintos, destacando cinco cursos com maior incidência de estudantes quilombolas: Pedagogia, Administração, Direito, Ciências Biológicas e Ciências Contábeis. Em relação a evasão, no período de 2017 a 2020 foram observados 68 alunos quilombolas que abandonaram o curso.

Os dados extraídos da pesquisa documental foram a base para a formação do universo pesquisado. Os sujeitos foram abordados inicialmente por meio de um formulário no Google forms, com o intuito de identificar os estudantes com condições de participar da próxima fase do estudo, a entrevista. Assim, nesse primeiro contato buscou-se identificar: e-mail; gênero; idade; comunidades de origem; curso; campus, polo ou núcleo que estuda; ano de ingresso; se pertence a associações ou grupos representativos dentro da UFPA e $o$ aceite em participar da segunda etapa da pesquisa.

\footnotetext{
2 Dados coletados em de maio de 2020
} 
Com as atividades acadêmicas suspensas, foi enviado o link do formulário para as lideranças representativas dentro da UFPA como: Associação de Discentes Quilombolas da UFPA-ADQ; Projeto Conexões e Saberes ICSA/UFPA; Projeto Indígenas e Quilombolas - Conhecimento e Resistência-IQ; Professores e Grupos de WhatsApp de alunos, para serem repassados para os sujeitos ou outros grupos que tivessem a possibilidade de contactar os discentes quilombolas. Toda essa mobilização resultou em 44 formulários respondidos, destes 14 formulários foram descartados, pelos seguintes motivos: respondentes em duplicidades, negativa em aceitar participar da segunda etapa da pesquisa e um sujeito que não se adequava ao critério de estudante quilombola. Desse modo, 30 estudantes estavam aptos para a segunda etapa.

As informações obtidas nessa etapa, possibilitaram algumas análises preliminares. Em relação ao gênero, 99\% dos respondentes são femininos e 1\% do masculino. Em termos de moradia, todos ainda vivem em suas comunidades, e tem que se deslocar para o Campus Belém ou para o Campus do município mais próximo. Quanto à idade, verificou-se a predominância de uma faixa etária de 21 a 30 anos, diferente dos estudantes não-quilombolas que ingressam nas universidades brasileiras com uma faixa etária de 18 a 24 anos, considerada "idade escolar típica" (ANDIFES, 2019). Foram identificados discentes de 18 comunidades quilombolas no estado do Pará. Embora a distância e a moradia sejam fatores negativos para a permanência desses discentes na vida acadêmica, o Campus Belém ainda é uma escolha predominante para os estudantes. Os cursos somaram 13, com destaque para os cursos: Serviço Social, Biblioteconomia e Arquivologia. Os respondentes mencionaram a atuação de associações representativas que apoiam os estudantes quilombolas no contexto da UFPA, desenvolvendo ações de enfrentamento perante as dificuldades acadêmicas. Verificou-se que 50\% dos participantes têm vínculos com essas representações.

Após a análise dessa primeira etapa foi agendado com 30 sujeitos a entrevista semiestruturada, mas os problemas causados pela pandemia e o acesso à internet fez com que apenas 16 sujeitos fossem entrevistados por chamada de áudio no whatsapp, seguindo um roteiro de 12 questões 
relacionadas às Práticas Informacionais e a visão histórica e cultural do cotidiano dos sujeitos.

A análise dos dados coletados nas entrevistas foi baseada na Análise Crítica do Discurso (ACD) por meio da dimensão prática social e suas categorias Ideologia e Hegemonia. De acordo com a ACD, a categoria Ideologia observa os aspectos do texto que podem ser investidos ideologicamente, como os sentidos das palavras, as pressuposições, as metáforas, o estilo. E a categoria Hegemonia verifica as orientações da prática social, que podem ser econômicas, políticas, ideológicas e culturais (RESENDE; RAMALHO, 2004).

Após a transcrição das entrevistas foi realizada a sistematização dos dados e criadas oito subcategorias (Quadro 2) relacionadas a temática principal da pesquisa - Práticas Informacionais, a dimensão da ACD - Prática social e suas categorias Hegemonia e Ideologia.

\section{Quadro 2 - Categorização dos dados}

\begin{tabular}{|c|c|c|c|}
\hline Temática & Dimensão & Categorias & Subcategorias \\
\hline \multirow{8}{*}{$\begin{array}{c}\text { Práticas } \\
\text { Informacionais }\end{array}$} & \multirow{8}{*}{$\begin{array}{l}\text { Prática } \\
\text { Social }\end{array}$} & \multirow{4}{*}{ Hegemonia } & Preservação e memória Histórica e Cultural \\
\hline & & & $\begin{array}{l}\text { Formação histórica/cultural relacionada ao ensino } \\
\text { superior }\end{array}$ \\
\hline & & & Transferência de conhecimento \\
\hline & & & Preconceito e discriminação \\
\hline & & \multirow{4}{*}{ Ideologia } & Representatividade \\
\hline & & & Acesso à Informação \\
\hline & & & Identificação das práticas informacionais \\
\hline & & & Percepção do pensamento crítico \\
\hline
\end{tabular}

Fonte: Elaborado pelas autoras (2021)

Assim, a partir dos discursos dos sujeitos, as subcategorias foram relacionadas com o referencial teórico. Apresenta-se a seguir a referida relação, bem como os discursos mais relevantes. Cabe ressaltar que neste artigo não foi possível transcrever todas as falas contidas na pesquisa original (COSTA, 2021).

Preservação e memória histórica e cultural (subcategoria 1): é referente à memória e vivência dos sujeitos enquanto remanescentes de uma 
comunidade quilombola, neste sentido, verificou-se as falas dos entrevistados quanto à preservação e à perda de suas tradições e como esse aspecto pode influenciar a sua identidade e o reconhecimento de suas origens. Nascimento e Marteleto (2004) enfatizam a importância da historicidade como elemento de ligação entre o passado e o presente dos indivíduos para constituir a sua identidade humana. Nessa perspectiva, entende-se que as dimensões históricas, culturais, econômicas, tecnológicas, sociais e políticas são précondições para o entendimento da 'informação'. Dessa forma, a informação deve ser referenciada à historicidade dos sujeitos, ao funcionamento das estruturas e das relações sociais e aos sujeitos que executam ações. Isto é, a potencialidade de se ver a informação constituída como problema da sociedade, configurado como um fenômeno da ordem cultural e da humanidade.

"[...] É uma comunidade pequena o inchaço das cidades tá diminuindo o território, devido às grandes invasões [...] o meio de tentar manter viva a nossa tradição, é através da nossa igreja que foi um símbolo da nossa luta e que nos ajudou a conseguir o documento que comprovasse que aqui era um quilombo remanescente". (Entrevistado)

"[...] hoje em dia, dentro das escolas, os professores tentam fazer esse processo de reafirmação pra trazer a nossa cultura, mas acredito que poucas coisas, que foram mantidas [...] se chega alguém lá de fora, não consegue identificar como uma comunidade quilombola, porque já foram perdidas muitas das nossas tradições. Conseguem identificar somente como uma comunidade rural." (Entrevistado)

"Então muitas coisas ainda se perderam, mas algumas coisas com o Círio lá da comunidade Santíssima Trindade ainda ocorre todo ano no mês de outubro, no terceiro final de semana, essa festividade lá que é esse ano foi realizado o $33^{\circ}$ Círio na cidade que a Padroeira da comunidade. Já tiveram outras tradições, e outras festas tradicionais." (Entrevistado)

Os discursos mostram o processo de perda das tradições dos sujeitos, e o quanto isso demonstra a sensação de descaso com as tradições que formaram o seu povo, e apontam alguns pontos causais para essa negligência, como por exemplo, o desenvolvimento das cidades que comprimem as comunidades mais próximas dos centros urbanos e contribuem para a sua descaracterização.

Ainda com relação aos aspectos histórico/cultural foram observadas as relações com as crenças, a religião, as datas comemorativas que constituem um conjunto de conteúdo simbólico e afetivo relacionado às experiências sociais e pessoais de cada sujeito. Marteleto (1995) enfatiza que essas marcações 
simbólicas podem ser utilizadas como justificativa para a validação das relações de opressão. No entanto, verificou-se nas entrevistas a falta de referência às religiões tradicionais de matriz africana, uma vez que o aspecto religioso reforça a identidade étnica. Além da religiosidade, outros elementos culturais aparecem de maneira e percepções distintas nas narrativas de cada sujeito. Nessa situação, a construção e a vivência do conteúdo histórico/cultural originada de um coletivo, provavelmente tem uma leitura particular para cada indivíduo.

\section{A formação histórica e cultural relacionada ao ensino superior} (subcategoria 2), levantou questões sobre a educação dos quilombolas, que revela uma realidade severa pela falta de ética de professores e colegas de sala de aula que avaliam esses estudantes como desqualificados e com capacidade intelectual inferior. É um discurso de poder baseado no fato de que os estudantes quilombolas só conseguiram acesso ao ensino superior porque se beneficiaram de um Processo Seletivo Especial, configurando-se em relação de poder. De acordo com Chouliaraki e Fairclough (1999), essa prática é uma tentativa de naturalizar as convenções discursivas, tornando um mecanismo extremamente eficaz na perpetuação e reprodução de dimensões culturais e ideológicas da hegemonia.

"Bom, o processo de cotas pelo qual nós fomos inseridos na UFPA, que é o PSE, processo especial, processo seletivo especial pra indígenas e quilombolas, ele é nada mais, nada menos, que um direito nosso, um é como se fosse uma retratação do governo brasileiro para com nosso, nossos antepassados que foram, que aqui foram explorados, porque vieram da África sendo livres e aqui se tornaram escravos. Então, essa retratação é tardia, mas é válida." (Entrevistado)

"Dentro da universidade não tem muito essa relação de procurar saber sobre as origens dos estudantes quilombolas, pouco se fala nisso na verdade, não tem muito interesse em preservar dentro da faculdade mesmo, essa cultura, essa história dos povos quilombolas, não tem muito isso na universidade". (Entrevistado)

"A trajetória histórica e Cultural ela é inserida como um ponto positivo na vida acadêmica é a nossa história que nos impulsiona a seguir em frente a nossa mobilização se refere em "juntos somos mais fortes'". (Entrevistado)

Foram observadas as lutas desses estudantes em valorizar e inserir a sua cultura no meio acadêmico, mesmo diante das dificuldades, são grandes as expectativas sobre o ensino superior relacionadas às lutas e reinvindicações por 
direitos para a sua comunidade.

Transferência do conhecimento (subcategoria 3) está estritamente ligada às crenças, identidade e culturas, desse modo determinados costumes ou conhecimento tradicionais estão relacionados com a memória social de grupos específicos. Assim, esse conhecimento armazenado vai interferir nos valores e nas práticas sociais reacendendo o modo de viver da coletividade. Por outro lado, o conhecimento referente a inovação e habilidades em aplicar os novos conhecimentos nas práticas do cotidiano é definido por Chouliaraki e Fairclough (1999) como um recurso de mudança social. Portanto, os recursos para a preservação das tradições por meio da transmissão de conhecimentos tradicionais das comunidades quilombolas é considerada como uma prática de mudança social e cultural.

"Inclusive a gente temos nossa festa tradicional do Dia da Consciência Negra, onde os mais velhos costumam passar todos os conhecimentos sobre dança, apresentações, algumas coisas mais da ancestralidade pra que não acabe essa tradição de nossa remanescência, assim passamos de geração em geração." (Entrevistado)

"Eu busquei me envolver naquilo que me tentasse me ligar minha comunidade. No meu caso eu trabalho em prol eu participo de projetos que tem justamente essa temática, porque trabalha com os quilombos daqui de Castanhal, justamente pra que eu não me distancie tanto da minha comunidade". (Entrevistado)

É importante evidenciar que as comunidades desenvolvem ações para dar continuidade às suas tradições, assim o relato de uma aluna exemplifica a aplicação de seu conhecimento acadêmico para dar continuidade ao conhecimento tradicional de sua cultura mostra o sujeito agindo de forma individual no interesse da coletividade contribuindo para mudanças do contexto social ao qual está inserido.

Preconceito e Discriminação (subcategoria 4) no contexto da UFPA, apontam a existência de racismo, discriminação social e educacional, nesse sentido a hegemonia manifesta-se para reforçar o papel do discurso no estabelecimento e na manutenção das relações de dominação, uma vez que a naturalização das representações particulares é fundamental para a permanência das articulações baseadas no poder (RESENDE, 2008). A reflexão sobre a trajetória acadêmica dos estudantes quilombolas levanta a problemática 
sobre o desempenho na aprendizagem, agravada por uma prática hegemônica produzida de modo consensual por ideologias que se propõem a dar continuidade a uma dominação exercida por elites, instituições ou grupos que ressaltam as desigualdades sociais. Essas reflexões e análises baseadas na categoria Hegemonia no contexto das práticas sociais, permitiram uma compreensão dos discursos dos entrevistados e a identificação de pontos que relacionam as desigualdades sociais que são usadas para justificar continuidade a um poder hegemônico presente no meio acadêmico.

"Com toda certeza esse preconceito e essa discriminação existem sim, e isso na grande maioria das vezes ocorre desde o momento que nos autoidentificamos e nos reconhecemos como pessoas negras, quilombolas e descendentes de quilombos.......] Minha visão é que esses temas precisam urgentemente ser tratados com mais importância e frequência nas universidades, que não sejam temas que venham ser trabalhados apenas em dias como o da consciência negra ou algo do tipo, é necessário desenvolver métodos para que se entenda a real importância de respeitar a nossa história e a nossa cultura". (Entrevistado)

"por sermos quilombolas, por nos autodeclararmos, porque as pessoas elas sempre acham que a gente entrou lá caiu de gaiato no navio, está lá porque nos foi dado algo que a gente nem merece estar lá, eles acham que não deveríamos estar lá". (Entrevistado)

A fala do entrevistado chama atenção para a urgência em discutir os temas preconceito e discriminação de forma constante e consistente dentro das universidades, ressalta que a UFPA deve estar preparada para receber os alunos quilombolas e que o acesso ao ensino superior por esse grupo social, evidencia $o$ preconceito e a necessidade de políticas que assegurem a permanência dentro da universidade.

As subcategorias de 5 a 8 fazem uma relação com a categoria Ideologia entendida como significações e construções da realidade (o mundo físico, as relações sociais, as identidades sociais) que são construídas em várias dimensões das formas e sentidos das práticas discursivas e que contribuem para a produção, a reprodução ou a transformação das relações de dominação. (FAIRCLOUGH, 2001, p. 117). Nesse sentido, as subcategorias foram analisadas de acordo com esses fundamentos.

Representatividade (subcategoria 5), entendemos que políticas assertivas estimulam a visibilidade e a formação acadêmica, não obstante, ainda existe uma cultura dominante, resultado de um capital cultural que reforça uma 
ideologia de não reconhecimento da identidade histórica e cultural dos sujeitos em questão, essa negação da instituição estimula a perpetuação da desigualdade e da discriminação.

"Sim, me sinto representada, por alguns professores, principalmente de história da arte e cultura. Também existem alguns autores negros que são falados nas bibliografias". (Entrevistado)

"Sim, por alguns professores de vários cursos, são professores que na maioria das vezes conhecem as nossas lutas e nossa realidade, pessoas sensíveis com a causa dos outros. Mais não é uma unanimidade na instituição. Quanto aos autores negros, não conheço não muitos, somos carentes nesse quesito, precisamos de mais referencias." (Entrevistado)

De acordo com o relato dos entrevistados de como eles percebem a representatividade nos espaços da UFPA, relacionados a professores, temáticas e bibliografias, conclui-se que ainda é baixa e o seu aumento está vinculado ao desenvolvimento de políticas afirmativas, em razão de somente o acesso ao ensino superior não possibilita a igualdade social. São citadas ações desenvolvidas na instituição para coibir as práticas de racismo ou qualquer tipo de preconceito.

Acesso à informação (subcategoria 6), os discursos apresentados relatam uma grande dificuldade em acessar, buscar e usar as informações, pois enfrentam e vivenciam um contexto socioeconômico diferente dos demais. A comprovação da demanda informacional é uma realidade que separa e discrimina grupos, sustentada por tecnologias, que representam muito mais do que o direito ao acesso à informação, pois ressalta uma ideologia de que existe uma democratização da informação. Dessa forma, os discursos ideológicos influenciam o conhecimento, os saberes, as crenças, atitudes e as informações. Isso significa dizer que a ideologia baseada na ACD propõe privilegiar grupos em detrimento de outros de forma institucionalizada e natural (FAIRCLOUGH, 2001). Em vista disso, a busca por cidadania, educação e informação pelos alunos quilombolas remete a agir de forma contraria a ideologia que já está enraizada nas instituições de ensino superior. No entanto, esse posicionamento dos estudantes em lutar por seus direitos, mesmo de forma moderada, o coloca como sujeitos sociais.

"A informação é muito importante, com esse tempo agora de muitas fake News, a gente tem que buscar fontes confiáveis, pra não se enganar, mas as pessoas 
desinformadas... é muito complicado, eu já passei por isso, de ficar sem informação, já tive vários danos, não digo só psicológicos como financeiros, por informações erradas, então é muito importante no que a gente vive, não importa como chega as informações, se for de fontes confiáveis é bem-vindo." (Entrevistado)

"A informação de forma correta, sem ser fake news, ela é muito importante pra gente se manter atualizada, pra gente saber ter um lado crítico, pra gente saber o que que tá se passando nesse mundo. A informação hoje, é a ponte que liga nós mesmos ao conhecimento. Vejo que ela pode tá inserida de várias formas no nosso cotidiano, antes eu não conseguia enxergar e agora eu estou enxergando, e trazendo isso, trazendo o meu curso pra dentro da minha comunidade... Que incrível...[...] De levar a informação para nossas comunidades, tá servindo de ponte pra acesso informação dessas comunidades. Hoje em dia, muita gente se mantém muito informado pelas redes sociais, mas nem tudo o que tá lá é verídico." (Entrevistado)

Eu procuro sites de confiança, e Facebook e no WhatsApp. Aparece algumas coisas, informação eu procuro checar se aquela informação é verdadeira. $E$ quanto aos recursos da UFPA, eu sinto que isso ainda não me alcança muito bem, entende? Mas acredito que é por questões de como funcionam as redes sociais, que eu não sei muito bem como funciona. E até porque, tenho um celular que já que é única, ou a única coisa que me possibilita ter essas informações que já é de baixa qualidade, então o meu alcance de informação se torna limitado por isso. E ainda tem o problema de equipamentos e a dificuldade em conhecer certos recursos que são disponibilizados na biblioteca. (Entrevistado)

Os entrevistados descreveram as fontes e estratégias informacionais utilizadas nas atividades individuais ou coletivas, são elas: Biblioteca, Internet, Jornais, livros, Televisão, Bases de dados, Redes sociais e Centro acadêmico. Os relatos mostram as dificuldades em acessar os recursos informacionais oferecidos pela universidade, como biblioteca e os serviços on line. Os impedimentos relatados são a falta de disponibilidade de internet e o pouco conhecimento em usar os equipamentos e os serviços oferecidos, essas questões são reflexos da carência de TICs no cotidiano das comunidades. Mesmo o acesso à internet sendo um dos problemas citados pelos estudantes quilombolas, configura-se como principal meio para obter a informação.

Identificação das Práticas Informacionais (subcategoria 7) mostram um perfil dos estudantes que estão cientes de sua condição de indivíduo que tem todo direito de ser reconhecido como sujeito ativo na sociedade melhorando suas perspectivas de vida por meio do ensino superior, além disso atuar como disseminador de conhecimentos em benefício da sua comunidade. As ideologias insinuadas nas entrevistas, refletem as ideias de Fairclough (2001a), pois se 
assemelham a uma prática de dominação que influenciam as relações discursivas, como prática educacional e prática econômica.

"Eu não acesso muito a biblioteca, eu acesso mais o meu e-mail no centro acadêmico, eu não sei manusear muito o computador, mas eu consigo fazer uma pesquisa, é lá que eu mantenho informada, olho algumas informações no Google, mas assim, eu não tenho, eu pouco acesso a biblioteca, eu nunca fui, na biblioteca central. Mas, assim, eu não, lá na UFPA como diz, eu não vou na biblioteca". (Entrevistado)

"Bem, as informações adquiridas ao longo do meu curso serão muito uteis com certeza, hoje vejo que a pedagogia na educação quilombola é aplicada de uma forma descontextualizada com a realidade local, então eu pretendo usar o meu conhecimento para mudar essa realidade. Por exemplo utilizando atividades que sejam realmente colocadas em prática no amplo espaço quilombola que possuímos, valorizando assim a cultura e a nossa história. Infelizmente muitos professores por serem de fora da comunidade acabam excluindo um pouco esse tipo de prática pedagógica da rotina deles." (Entrevistado)

Então acredito que todo conhecimento que eu tenho adquirido é pra levar pra nossa comunidade. E no meu curso enquanto estudante de serviço social eu creio que poderei contribuir muito tanto com informação como com o meu trabalho dentro de alguma instituição lá na minha comunidade". (Entrevistado)

Por esse ângulo, as análises demonstram a preocupação dos estudantes em relação a veracidade das informações e como esse conhecimento adquirido vai influenciar e contextualizar com a realidade das suas comunidades. Foram verificadas atuações que caracterizam as Práticas Informacionais dos estudantes quilombolas em um fluxo de compartilhamento, ações de recepção, geração e transferência de informações por meio de atividades que são desenvolvidas no contexto da universidade e das comunidades como: Reuniões da $A D Q$, meio de buscar informações; Reuniões de grupos de quilombolas para compartilhamento de informações, Reuniões com jovens e crianças da Comunidade para transmissão de conhecimento, participação em palestras, Elaboração de projetos para serem aplicados na comunidade, aplicação na prática do aprendizado no curso de graduação para a preservação histórica e cultural. Todas essas Práticas informacionais que estão sendo desenvolvidas configuram-se como uma contextualização da informação adquirida no meio acadêmico em consonância com a realidade dos quilombolas.

Percepção do pensamento crítico (subcategoria 8), reflete dados que 
podem ser vistos como um posicionamento contrário à ideologia de poder das informações que são disseminadas sem critério de autenticidade e à falta de divulgação de informações de interesse da sociedade que muitas vezes são mascaradas ou negadas. Dessa forma, a ação de contribuir com o coletivo na apropriação da informação, faz com que esses estudantes procurem eliminar por meio das práticas informacionais as situações ideológicas se colocando na sociedade como produtor de material informacional e não somente como consumidor dessas informações.

"Sim, a informação é capaz disso, dessa mudança da sociedade para mundo melhor, pra vivermos melhor. Temos sim, a partir do momento que todos e todas decidirem numa mesma posição, numa mesma direção, com objetivo de melhorias de igualdade, para todos e todas, independente de classes, de raças, de enfim, de tudo que que nós tivemos na nossa sociedade, eu acho que a informação a partir desse momento, ela pode sim fazer total diferença na nossa, nossa vivência, na nossa sociedade." (Entrevistado)

"Sim pessoas informadas são mais conhecedoras do mundo, da sociedade e das lutas dos negros. Se conhecemos a história do outro é que criamos empatia pelo outro. Acho que as pessoas que têm essa informação, que sabe que a trajetória dos negros foi difícil, são menos preconceituosas, menos racistas, mais empáticas." (Entrevistado)

"Sim eu considero, se soubermos utilizar essas informações da maneira correta, de forma a fazer com que um indivíduo realmente absorva a importância de determinada temática, e reflita em cima desse conhecimento, isso poderá despertar nele um possível desejo de mudança". (Entrevistado)

Os depoimentos denotam que mesmo carentes de informação, existe uma conscientização sobre o poder da informação na transformação dos indivíduos. Mesmo de forma tímida a Competência Crítica em Informação está presente nas relações de preconceito, discriminação econômica, social e cultural imposta pela sociedade. É interessante observar o caráter coletivo que aparecem nos discursos, colocando a informação sempre para melhoria da comunidade, como fortalecimento da trajetória cultural e conhecimento de seus direitos.

Para verificar como a Competência Crítica em Informação pode influenciar as Práticas Informacionais identificadas na coleta de dados, fez-se uma análise, tendo como base o referencial teórico das temáticas centrais e os resultados da Análise crítica do discurso, configurando-se como uma triangulação dos resultados. Primeiramente é significativo mencionar as relações conceituais 
entre as duas temáticas, Práticas Informacionais e Competência Crítica em Informação. Foram observados por ocasião da construção do referencial teórico que as duas abordagens promovem a compreensão do valor da informação e sua influência sobre os indivíduos em qualquer contexto, assim como, um aprendizado informacional autônomo e independente ao longo da vida por meio do desenvolvimento de ações que produzam mudanças sociais.

Com base nos resultados é possível afirmar dificuldade que as comunidades quilombolas tem em transmitir as tradições para a gerações futuras e a falta de ações que incentivem um diálogo entre a história cultural dos estudantes e o meio acadêmico, colaboram para que as desigualdades sociais permaneçam interferindo nas práticas sociais dos estudantes

Para inserir reflexões sobre Competência Crítica em Informação, procedeu-se relações entre as análises e o aprendizado ao longo da vida, definido como um "processo contínuo de internalização conceituais, atitudinais e de habilidades necessárias à compreensão e interação permanente com a dinâmica universo informacional" (DUDZIAK, 2003, p. 6) acrescidos de desafios tecnológicos, econômicos, sociais e culturais. Nesse sentido, a CCI requer um posicionamento crítico e ético sobre as necessidades informacionais. De acordo com os discursos analisados, as necessidades informacionais dos estudantes quilombolas tem uma preocupação individual e coletiva, com prioridade para a busca de informações no acesso ao ensino superior. A fala dos entrevistados ressalta o compromisso de aplicação do conhecimento adquirido na vida acadêmica em benefício das comunidades para mudar a realidade do cotidiano dos seus.

A busca por informações relevantes para as comunidades, configura-se como uma necessidade de informações sobre seus direitos como cidadão. Nesse caso são citados a "Associação de Estudantes Quilombolas" e o "Projeto de Extensão IQ-Conhecimento e Resistência", espaços informais de representação, criados dentro da UFPA para exercer um papel de mediador na disseminação de informações necessárias sobre direito, ensino e aprendizado para os estudantes. Pelo posicionamento de alguns entrevistados percebeu-se que esses espaços têm ainda a função de conscientizar esses alunos para se 
posicionarem criticamente em relação as informações e aos conflitos diários. As atitudes tomadas no enfrentamento à violência, desigualdades sociais, culturais e econômicas orienta para o desenvolvimento do pensamento crítico. A prática questionadora que faz parte do pensamento crítico, foi identificada nas análises como situações de preconceito, discriminação, falta de representatividade, adaptação e permanência no ensino superior. A legitimação desses estudantes que sofrem com exclusão histórica requer mais que ações políticas de informações.

Ainda na triangulação de dados buscou-se relacionar os resultados das análises aos sete níveis da Competência Crítica em Informação de Schneider (2019) e assim observar o sentido crítico das vivências informacionais dos estudantes quilombolas da UFPA.

1ำ nível - Concentração: a necessidade informacional está em adquirir informações e conhecimentos em um curso de graduação para superar barreiras e discriminações, possibilitando para a sua comunidade novas oportunidades. Como foi citado nas entrevistas, o uso da internet é o principal recurso utilizado, mas em meio ao volume informacional pode ocorrer a inibição de necessidades informacionais mais relevantes.

2o nível - Instrumental: capacidade de lidar com os recursos informacionais e TICs, foram citados a dificuldade com ensino remoto, que foi comentado por todos os entrevistados, as dificuldades em acessar as informações e a falta de conhecimento com equipamento e plataformas virtuais, eleva as desigualdades sociais e amplia a dificuldade de inserção no contexto universitário.

3ำ nível - Gosto: as necessidades informacionais estão vinculadas a formação histórica/cultural e as experiencias ao longo da vida influenciam o capital cultural dos estudantes quilombolas, fruto de uma educação discriminatória refletida no aprendizado acadêmico. Então a inclusão desses alunos na pesquisa induz a produção de informações.

4o nível - Relevância: preocupação em verificar a origem das informações e como essas informações podem prejudicar as pessoas. Os 
estudantes desempenham um papel importante no fluxo da informação da comunidade entendem que a relevância e a confiabilidade de determinadas informações é uma forma de conscientização dos membros das comunidades para que os mesmos não sejam enganados. A ausência de critérios de relevância das informações leva ao desenvolvimento de práticas informacionais nem sempre apropriadas.

5o nível - Credibilidade: é a busca de fontes de informações confiáveis, os estudantes relataram que procuraram associações, palestras a fim de verificar a veracidade das informações que são repassadas para a comunidade. Para conscientizá-la do uso correto das redes sociais, e não repassarem informações duvidosas.

60 nível - Ética: as práticas informacionais efetivas são influenciadas pela forma como os estudantes recebem as informações na sala de aula, físicas ou virtuais. De acordo com estudantes os conteúdos ofertados e os professores não consideram a historicidade e a cultura: o ensino básico, o aspecto social e econômico. Os pontos ressaltados pelos alunos sobre o ensino remoto, demonstra um desequilíbrio que não favorece o aprendizado.

70 nível - Crítica: Ao analisar todos os outros níveis, não é possível verificar uma articulação satisfatória em todos os níveis, a emancipação informacional dos estudantes quilombolas ainda conta com vários obstáculos. Observou-se nos discursos um pensamento crítico, questionamentos, reconhecimento da informação como elemento transformador nas desigualdades sociais e preocupação com as fontes de informação. No entanto, essas práticas necessitam de ações para o desenvolvimento de Competência Crítica em Informação.

As percepções sobre os resultados dessa pesquisa esclarecem que as temáticas abordadas, não somente colaboram com a emancipação informacional dos estudantes quilombolas, como também incentivam o empoderamento por meio de valores sociais na luta pela inclusão. Por consequênvcia, os resultados apontam a influência da Competência Crítica em Informação nas Práticas Informacionais dos estudantes quilombolas da UFPA, 
uma vez que essas práticas se configuram como ações para o enfrentamento das adversidades impostas desde o ensino base ao ingresso na universidade.

\section{CONSIDERAÇÕES FINAIS}

A pesquisa apresentada identifica e analisa as Práticas Informacionais e as suas influências na construção da Competência Crítica em Informação dos estudantes quilombolas da Universidade Federal do Pará relacionados aos desafios do ingresso ao ensino superior e à vivência no meio acadêmico. Por meio de relatos sobre a trajetória histórica/cultural foi possível compreender a influência que essa formação traz ao contexto acadêmico.

Conforme as respostas dos entrevistados, a perda das tradições históricas e culturais influenciam na construção da identidade, na preservação das crenças, na manutenção do território e no reconhecimento étnico-racial, uma vez que o estudante quilombola quando ingressa na universidade traz toda essa vivência de perdas e de negações que se somam às questões evidenciadas no âmbito acadêmico como: o preconceito e a discriminação; a adaptação a um local completamente novo, a falta de acolhimento e o aspecto econômico e social são alguns dos problemas que afetam a permanência desses estudantes no ensino superior. Ademais, o percurso acadêmico para os quilombolas torna-se um desafio pela falta de representatividade, de conteúdos de aprendizado que tenham relação com a historicidade e as ações afirmativas que visem não somente 0 ingresso desses alunos, mas também a permanência e 0 pertencimento deles na instituição.

Por tudo que foi exposto e pela proposta da pesquisa, buscou-se analisar não somente as Práticas Informacionais, apesar disso, o contexto social dos sujeitos e da instituição, nesse sentido, o acesso à informação ainda passa por impedimentos, como falta de disponibilidade de internet e o pouco conhecimento em usar os equipamentos e o acesso aos serviços oferecidos, essas questões são reflexos da carência de tecnologias no cotidiano das comunidades.

Vale destacar que as experiências relatadas pelos estudantes apontam que o capital cultural herdado e o quadro de exclusão impactam na construção de Práticas Informacionais. Nessa concepção, os espaços associativos dentro 
da universidade foram descritos pelos estudantes como locais de acolhimento atuando como mediadores de informações, em vista disso, acredita-se que esses locais possam incentivar a reflexão crítica dos estudantes quilombolas. A respeito dos recursos informacionais e das TICS, é uma realidade que não contempla a maioria dos alunos, e considerando o cenário de pandemia da Covid-19 (período em que foi desenvolvida a pesquisa), a exclusão aumentou em razão do ensino remoto. Essa foi uma questão unânime nas entrevistas.

Foi constatado que a Competência Crítica em Informação influencia a busca e o uso da informação, a diversidade de contextos, compartilhamento de ideias, questões sociais, políticas e culturais e mudanças sociais. Todos esses aspectos colaboram para a autonomia informacional do sujeito, deste modo, a construção de Práticas Informacionais adequadas requer o desenvolvimento de Competência Crítica em Informação. O desenvolvimento da pesquisa possibilitou um conhecimento a respeito dos estudantes quilombolas da UFPA, em relação às desigualdades educacionais, culturais, sociais e econômicas, fatores que contribuem para seu desempenho de aprendizado no ensino superior.

Conclui-se que as ideias desenvolvidas nesta investigação contribuem principalmente para a concretização de ações práticas relacionadas ao desenvolvimento da Competência Crítica em Informação para os quilombolas e outros grupos discriminados socialmente em suas Práticas Informacionais. E assim, apoiar o processo de construção do conhecimento ratificando o caráter social da Ciência da Informação e a pertinência da expansão de estudos para grupos sociais de raça e de gênero, além de reafirmar e de promover uma política de inclusão informacional.

\section{REFERÊNCIAS}

ANDIFES. Pesquisa do perfil socioeconômico e cultural dos estudantes de graduação das Instituições Federais de Ensino Superior Brasileiras, 5, 2018. Brasília, DF.: FONAPRACE, 2019. Disponível em: https://www.andifes.org.br/wp-content/uploads/2019/05. Acesso em: 23 jan. 2021 
ARAÚJJ, E. A. de. Informação, sociedade e cidadania: gestão da informação no contexto de organizações não-governamentais (ONGs) brasileiras. Ciência e Informação, Brasília, v. 29, n. 2, p. 155-167, maio/ago. 1999. Disponível em: https://www.scielo.br/scielo.php?pid. Acesso em: 29 maio 2020.

ARAÚJO, C. A. A. Paradigma social nos estudos de usuários da informação: abordagem interacionista. Informação \& Sociedade: Estudos, João Pessoa, v. 22, n. 1, p. 145- 159, jan./abr. 2012. Disponível em:

https://www.brapci.inf.br/index.php/res/v/91416. Acesso em: 23 maio 2020.

ARAÚJO, C. A. A. O sujeito informacional no cruzamento da Ciência da Informação com as Ciências Sociais. In: ENCONTRO NACIONAL DE PESQUISA E PÓS-GRADUAÇÃO EM CIÊNCIA DA INFORMAÇÃO (ENANCIB), 14., 2013, Florianópolis. Anais [...]. Florianópolis: UFSC, ANCIB, 2013.

BRASIL. Lei no 10.639, de 9 de janeiro de 2003. Altera a Lei no 9.394, de 20 de dezembro de 1996, que estabelece as diretrizes e bases da educação nacional, para incluir no currículo oficial da Rede de Ensino a obrigatoriedade da temática "História e Cultura Afro-Brasileira", e dá outras providências. Diário Oficial da União, Brasília, DF, 10 de janeiro de 2003, p. 01. Disponível em: http://www.planalto.gov.br/ccivil_03/leis/2003/110.639.htm. Acesso em: 1 jul. 2020.

BRASIL. MINISTÉRIO DA EDUCAÇÃO. Diretrizes Curriculares Nacionais para a Educação das Relações Étnico-Raciais e para o Ensino de História e Cultura Afro-Brasileira e Africana. Brasília/DF, SEPPIR, 2004. CNE/CP Resolução 1/2004. Diário Oficial da União, Brasília, DF, 22 de junho de 2004, Seção 1, p. 11. Disponível em: http://portal.mec.gov.br/cne/arquivos/pdf/res012004.pdf. Acesso em: 14 abr. 2020.

CAMPOS, L. R. Do quilombo à universidade: trajetórias, relatos, representações e desafios de estudantes quilombolas da Universidade Federal do Pará-Campus Belém quanto à permanência. 2016. 133 f. Dissertação (Mestrado em Educação) - Universidade Federal do Pará, Instituto de Ciências da Educação, Belém, 2016.

CARRIL, L. de F. B. Os desafios da educação quilombola no Brasil: o território como contexto e texto Universidade Federal de São Carlos, Sorocaba, SP.

Revista Brasileira de Educação, v. 22, n. 69, abr./jun. 2017. Disponível em: https://www.scielo.br/pdf/rbedu/i. Acesso em: 22 jan. 2020.

CHOULIARAKI, L.; FAIRCLOUGH, N. Discourse in Late Modernity:

Rethinking Critical Discourse Analysis. Edinburgh: Edinburgh University Press, 1999. Disponível em: https://www.researchgate.net/m. Acesso em: 10 jan. 2021.

COSTA, Maria Ivone Maia da. Práticas Informacionais e Competência Crítica em Informação de estudantes quilombolas da Universidade 
Federal do Pará, 2021, 214 f. Dissertação (Mestrado) - Programa de PósGraduação em Ciência da Informação, Instituto de Ciências Sociais Aplicadas, Universidade Federal do Pará, Belém, 2021.

DUDZIAK, E. A. Information literacy: princípios, filosofia e prática. Ciência da Informação, Brasília, v. 32, n. 1, p. 23-25, jan./abr. 2003. Disponível em: http://revista.ibict.br/ciinf/article/view/1016. Acesso em: 14 jul. 2020.

ELMBORG, J. Critical Information Literacy: Definitions and Challenges. In: WILKINSON, C. W.; BRUCH, C. (ed.). Transforming Information Literacy Programs: Intersecting Frontiers of Self, Library Culture, and Campus Community, 2012. p. 75-95. Disponível em: https://iro.uiowa.edu/discovery/fulldisplay/alma9983557574202771/01IOWA_IN ST:ResearchRepository. Acesso em: 10 nov. 2020.

FAIRCLOUGH, N. Discurso e mudança social. Brasília, DF.: UNB, 2001a.

FERES JUNIOR, J.; DAFLON, V. T. Políticas da Igualdade Racial no Ensino Superior. Cadernos do Desenvolvimento Fluminense, n. 5, 2014. Disponível em: https://www.e-publicacoes.uerj.br/index.php/cdf/article/. Acesso em: 10 jun. 2020.

FERREIRA, E. G. A.; ABREU, F. F.; LIMA, G. M. C. DE; SÁ, J. P. S. de. A construção do conceito de Práticas Informacionais pelos pesquisadores do EPIC. Informação em Pauta, Fortaleza, v. 4, n. esp., p. 26-43, maio 2019. Disponível em: http://www.periodicos.ufc.br/informacaoempauta/. Acesso em: 23 jan. 2020.

FLECK, A. Afinal de contas, o que é teoria crítica? Princípios: Revista de Filosofia, Natal, v. 24, n. 44, p. 97-127, maio/ago. 2017. Disponível em: https://periodicos.ufrn.br/principios/article/view/12083/pdf. Acesso em: 6 abr. 2021.

GOMES, N. L. Diversidade étnico-racial, inclusão e equidade na educação brasileira: desafios, políticas e práticas. Revista Brasileira de Política e Administração da Educação - RBPAE, Brasília, v. 7, n. 1, p. 109-121, jan./abr. 2011. Disponível em: https://seer.ufrgs.br/rbpae/article/. Acesso em: 1 jun. 2020.

GONZÁLEZ TERUEL, A. Los estudios de necesidades y usos de la información: fundamentos y perspectivas actuales. Gijon, Espanha: Trea, 2005.

LIMA, A. T. de O.; ARAÚJO, I. C. de; SILVA, W. M. S. da; PORTELA, R. de S. A trajetória das políticas de ações afirmativas para indígenas e quilombolas na Universidade Federal do Pará. In: JORNADA INTERNACIONAL DE POLÍTICAS PÚBLICAS, 8., 2015, São Luís. Anais [...]. São Luís: UFMA, 2015. 
MARTELETO, R. Cultura informacional: construindo o objeto informação pelo emprego dos conceitos de imaginário, instituição e campo social. Ciência da Informação, Brasília, v. 24, n. 1, p. 89-93, jan./abr. 1995. Disponível em: http://revista.ibict.br/ciinf/article/view/613: Acesso em: 25 mar. 2020.

NASCIMENTO, D. M.; MARTELETO, R. A "informação construída" nos meandros dos conceitos da teoria social de Pierre Bourdieu. DataGramaZero, v. 5, n. 5, 2004. Disponível em: http://hdl.handle.net/20.500.11959/brapci/. Acesso em: 10 mar. 2021.

RESENDE, V. de M. Análise de discurso crítica e etnografia: o movimento nacional de meninos e meninas de rua, sua crise e o protagonismo juvenil. 2008. 332 f. Tese (Doutorado em Linguística) - Universidade de Brasília, Brasília, 2008. Disponível em: https://repositorio.unb.br/. Acesso em: 10 fev. 2021.

RESENDE, V. de Melo; RAMALHO, V. C. V. S. Análise de discurso crítica, do modelo tridimensional à articulação entre práticas: implicações teóricometodológicas. Linguagem em (Dis)curso - LemD, Tubarão, v. 5, n. 1, p. 185-207, jul./dez. 2004. Disponível em: http://www.portaldeperiodicos.unisul.br. Acesso em: 10 fev. 2021.

SAVOLAINEN, R. Everyday life information seeking approaching information seeking in the context of "way of life". Library \& Information Science Research, Amsterdam, v. 17, n. 3, p. 259-294, 1995. Disponível em: https://www.sciencedirect.com/science/article/. Acesso em: 4 out. 2019.

SCHNEIDER, M. CCI/7: competência crítica em informação (em 7 níveis) como dispositivo de combate à pós-verdade. In: BEZERRA, A. C. B.; SCHNEIDER, M.; PIMENTA, R. M.; SALDANHA, G. S. (org.). iKrítika: estudos críticos em informação. Rio de Janeiro: Garamond, 2019. p. 73-116.

TEWELL, E. A decade of critical information literacy: a review of the literature. Communications in Information Literacy, v. 9, n. 1, p. 24-43, 2015. Disponível em: https://files.eric.ed.gov/fulltext/EJ1089135.pdf. Acesso em: 21 dez. 21.

UNIVERSIDADE FEDERAL DO PARÁ. Resolução no 4.309, de 27 de agosto de 2012. Fica aprovada a reserva de 2 (duas) vagas, por acréscimo, em favor dos quilombolas, no Processo Seletivo (PS) para ingresso nos cursos de graduação da Universidade Federal do Pará. Disponível em: http://www.proeg.ufpa.br/images/Artigos/Normas/resolu. Acesso em: 12 maio 2020. 


\title{
THE CONTRIBUTIONS OF THE CRITICAL INFORMATION LITERACY IN THE INFORMATIONAL PRACTICE OF QUILOMBOLA STUDENTS IN THE HIGHER EDUCATION: RESEARCH REPORT
}

\begin{abstract}
Objectives: To analyze within a historical, social and cultural context, the Informational Practices of quilombola students at the Federal University of Pará, in order to contribute to the elaboration of affirmative actions, with the perspective of minimizing the problem of access to information faced by these subjects. Methodology: Qualitative research divided into three stages: the first presents a bibliographic research; the second stage presents the development of the research, in which are included the documentary research that allowed tracing an overview about the presence of quilombola students enrolled in the institution; an ethnographic research, with the application of a questionnaire in google forms and a semi-structured interview. The data were analyzed under the foundations of Critical Discourse Analysis and in the third stage the triangulation of the data obtained in the previous stages was developed. Results: They indicate that the informational practices developed by quilombola students in the academic field and in the community field have a social interaction, demonstrating a criticality in informational actions. Conclusions: the ideas developed in this research contribute mainly to the realization of practical actions and the generation of fundamental knowledge on the issues of social and cultural inequalities within the researched context.
\end{abstract}

Descriptors: Information practices. Quilombola students. Critical information literacy.

\section{LOS APORTES DE LA COMPETENCIA CRÍTICA EN INFORMACIÓN EN LAS PRÁCTICAS INFORMATIVAS DE LOS ESTUDIANTES QUILOMBOLAS EN LA EDUCACIÓN SUPERIOR: UN INFORME DE INVESTIGACIÓN}

\begin{abstract}
RESUMEN
Objetivos: Analizar, dentro de un contexto histórico, social y cultural, las Prácticas Informativas de los estudiantes quilombolas de la Universidad Federal de Pará, con el fin de contribuir al desarrollo de acciones afirmativas, con vistas a minimizar el problema de acceso a la información que enfrentan estas personas. Metodología: Investigación cualitativa dividida en tres etapas: la primera presenta una investigación bibliográfica; la segunda etapa presenta el desarrollo de la investigación, que incluye una investigación documental que permitió trazar un panorama sobre la presencia de los estudiantes quilombolas matriculados en la institución; una investigación etnográfica, con la aplicación de un cuestionario en formularios google y una entrevista semiestructurada. Los datos se analizaron bajo los fundamentos del Análisis Crítico del Discurso y en la tercera etapa se desarrolló la triangulación de los datos obtenidos en las etapas anteriores. Resultados: indican que las Prácticas Informativas desarrolladas por los
\end{abstract}


estudiantes quilombolas en el ámbito académico y en el ámbito comunitario tienen una interacción social, demostrando una criticidad en las acciones informativas. Conclusiones: las ideas desarrolladas en esta investigación contribuyen principalmente a la realización de acciones prácticas y a la generación de conocimientos fundamentales en los temas de desigualdades sociales y culturales dentro del contexto investigado.

Descriptores: Prácticas informativas. Estudiantes de Quilombola. Competencia informativa crítica.

Recebido em: 2021.09.07

Aceito em: 2021.12.09 